\title{
OROGRAPHIC INFLUENCE ON DEEP CONVECTION: CASE STUDY AND SENSITIVITY EXPERIMENTS
}

\author{
S. Davolio, A. Buzzi, P. Malguzzi \\ ISAC-CNR Via Gobetti, 10140129 Bologna, Italy \\ E-mail: S.Davolio@isac.cnr.it
}

\begin{abstract}
The non hydrostatic convection resolving model MOLOCH is employed in order to evaluate its capability to realistically simulate the evolution of a mesoscale convective system responsible for an episode of heavy rainfall and flood over southeastern France (Gard event). Numerical experiments indicate large sensitivity of precipitation amounts and distribution, due to different cell organization and propagation, to the specification of the initial conditions.

Further experiments, aimed at studying the role played by the orography in triggering the convection and controlling its evolution, have been performed in order to characterize sensitivity to ambient wind and orography. Although the convective system remained almost stationary for many hours with maximum precipitation located at some distance upstream of the mountain main slope, simulations demonstrate that the presence of the orographic barrier is essential for both triggering and maintaining the mesoscale convective system. The intensity of precipitation turns out to be sensitive to small variations of the mean meridional wind component.
\end{abstract}

Keywords - convection, orography, precipitation

\section{INTRODUCTION}

Heavy precipitation and floods often derive from quasi-stationary convective systems where orography plays an important role in triggering convection and controlling its subsequent evolution. An example is provided by the flood event of 8-9 September 2002, occurred over the Gard region (southeastern France), characterized by the development of a mesoscale convective system (MCS) which remained almost stationary near the southern flank of the Massif Central. This MCS developed in a prefrontal meridional flow advecting moist air from the Western Mediterranean. Heavy rainfall, up to more than $600 \mathrm{~mm} / 24 \mathrm{~h}$, was recorded at some distance upstream of the main mountain slopes (Ducrocq et al., 2003).

This event represents a case of very intense convective activity and seems therefore suitable for testing the convection resolving model MOLOCH, recently developed at ISAC-CNR (for a detailed description see Drofa and Malguzzi, 2004, Buzzi et al., 2004) as a tool for very high resolution shortrange weather prediction and research studies.

The role played by the orography is investigated both with realistic and more idealized conditions. The theoretical and experimental framework is that proposed in a number of recent MAP-related studies of convectively unstable flows over orography (see, for example, Bousquet and Smull, 2003; Stein, 2004).

\section{IMPACT OF INITIAL CONDITIONS}

Simulations were initiated at 00, 06 and 12 UTC, 8 September 2002, in order to analyse the impact of different initial conditions on quantitative precipitation forecasts (QPF). The model horizontal resolution is $0.02^{\circ}$, with 50 levels in terrain-following coordinates. The model grid is nested in the BOLAM hydrostatic model, which in turn is driven by the ECMWF analyses. The accuracy of the simulations varies widely among the experiments. The run initiated with the 06 UTC analysis gives the best reproduction of the characteristics of the MCS, particularly in the first phase of its evolution. The MCS develops near the coast, moving slowly north-eastward and then becoming nearly stationary over the 
Gard region (Fig.1, left panel). The precipitation amount is slightly overpredicted in comparison with analysed observations (Fig. 1 right panel). Neither the experiments starting at 00 and 12 UTC develop the convection over the plains. Instead, convective activity is directly triggered by the orographically forced uplift and the precipitation pattern is displaced several tens of km northward, over the Massif Central. In the second phase of the event, between 00 and 06 UTC of 9 September, all simulations tend to produce rainfall to the north, that is over the slopes of the Massif Central, with respect to the observations. In the final phase of the event the MCS starts moving south-eastwards along with the incoming cold front. The model realistically reproduces the progression of the front and forecasts additional intense frontal precipitation over the Gard region.

From the analysis of the observed low-level wind field it appears that an area of pronounced convergence just inshore is present at the time of convective activity initiation. The south-easterly flow from the Mediterranean Sea turns abruptly, becoming north-easterly ahead of the orographic barrier, nearly parallel to the terrain contours. An estimation of the orographic Froude number gives a value around 1.5. Only the experiment starting at 06 UTC correctly reproduces this feature.
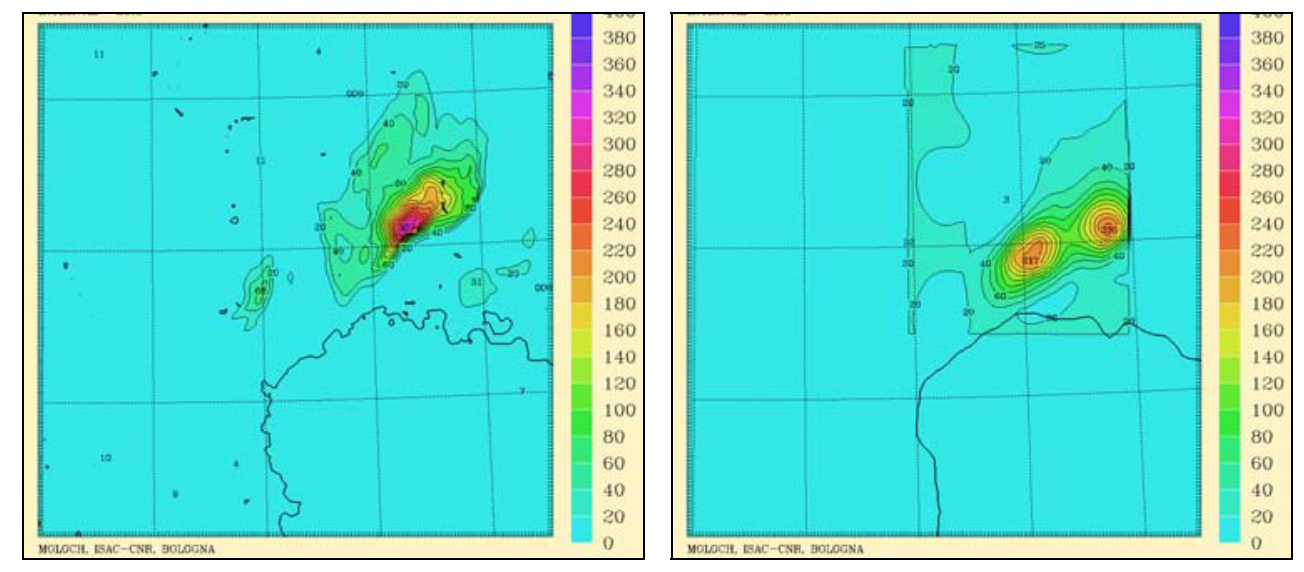

Figure 1. 12h accumulated precipitation at 21 UTC, 8 Sep. 2002, from a $15 \mathrm{~h}$ MOLOCH simulation (left panel) and raingauge observations (right panel).

\section{SENSITIVITY EXPERIMENTS}

\subsection{Height of orography}

Experiments were performed in order to investigate the role of the orography in triggering the convection and controlling its subsequent evolution. The simulations were initialized using the same atmospheric conditions, but modifying the height of the model orography over the central part of the domain (the Alps and the Pyrenees remain unchanged). When the height of the Massif Central is reduced by a factor of two, convection does not develop in the morning of 8 September over the plain, between the coast and the mountains, but starts later and appears well to the north (Fig. 2, left panel) of the area of the event, moving along the south-eastern flank of the Massif Central. At variance with the control simulation, the south-easterly flow from the sea in the lower troposphere is only weakly deflected during the first hours as the orography is not able to effectively block the flow. Therefore, after a few hours the low-level wind becomes oriented across the orographic barrier and the convection is triggered further downstream.

When the height of the Massif Central is enhanced by a factor 1.25, the MCS remains nearly stationary as in the reference run, but precipitation accumulates more to the south, over an area almost coincident with the observations (Fig. 2, right panel). 


\subsection{Meridional wind intensity}

Simple considerations based on the Froude number suggest that transition between orographic flow regimes can be obtained by changing the intensity of the wind speed across the orographic slope. A number of experiments have been made by adding a barotropic component in geostrophic equilibrium to the initial and boundary conditions. Fig. 3 left (right) shows the accumulated precipitation obtained by adding (subtracting) $2 \mathrm{~m} / \mathrm{s}$ to the $\mathrm{v}$-component. It can be noticed that cumulated precipitation is very sensitive to variations of this parameter. The maximum precipitation is obtained in the control experiment (left panel of Fig. 1); in this case the observed wind corresponds to the v-component which maximizes precipitation. This behaviour cannot be understood by assuming that the characteristics of the flow are a function of the Froude number alone. It is clear that the fully developed MCS strongly perturbs the upstream basic flow. In order to better understand the nature of this phenomenon, the interaction between the MCS circulation and orography must be analyzed, including the formation and role played by the cold pool ahead of the orography itself and the effect of the intensity of the upstream flow which feeds the updraft.
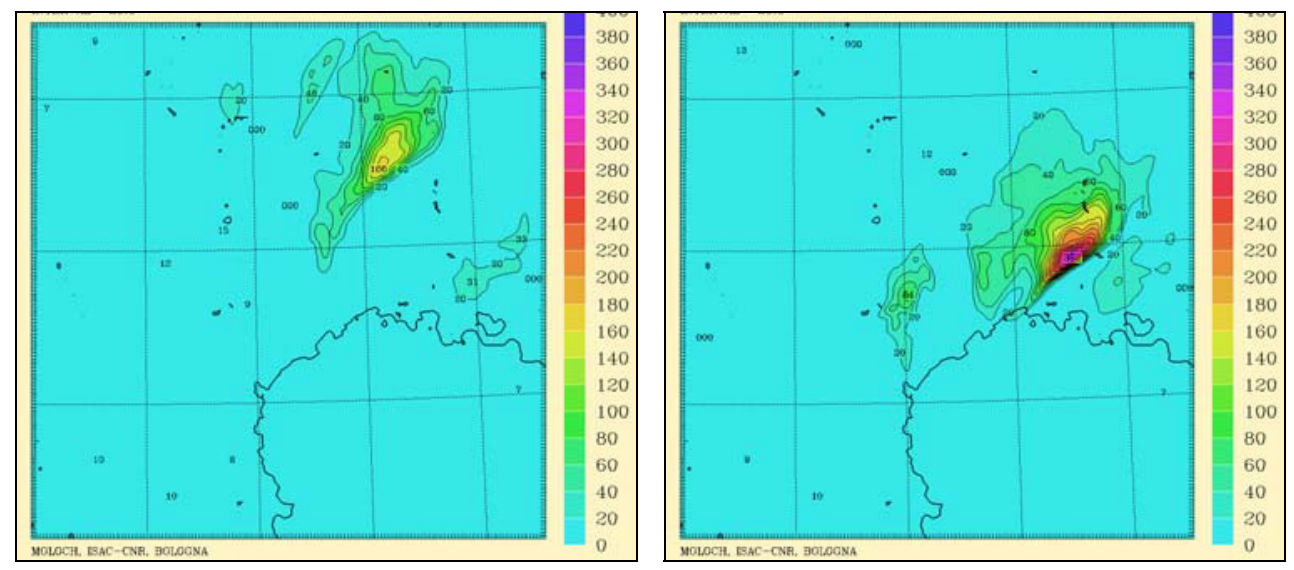

Figure 2: $12 \mathrm{~h}$ accumulated precipitation at $21 \mathrm{UTC}, 8 \mathrm{Sep} .2002$, from a $15 \mathrm{~h}$ MOLOCH simulation. Left panel: orography multiplied by 0.5 . Right panel: orography multiplied by 1.25 .
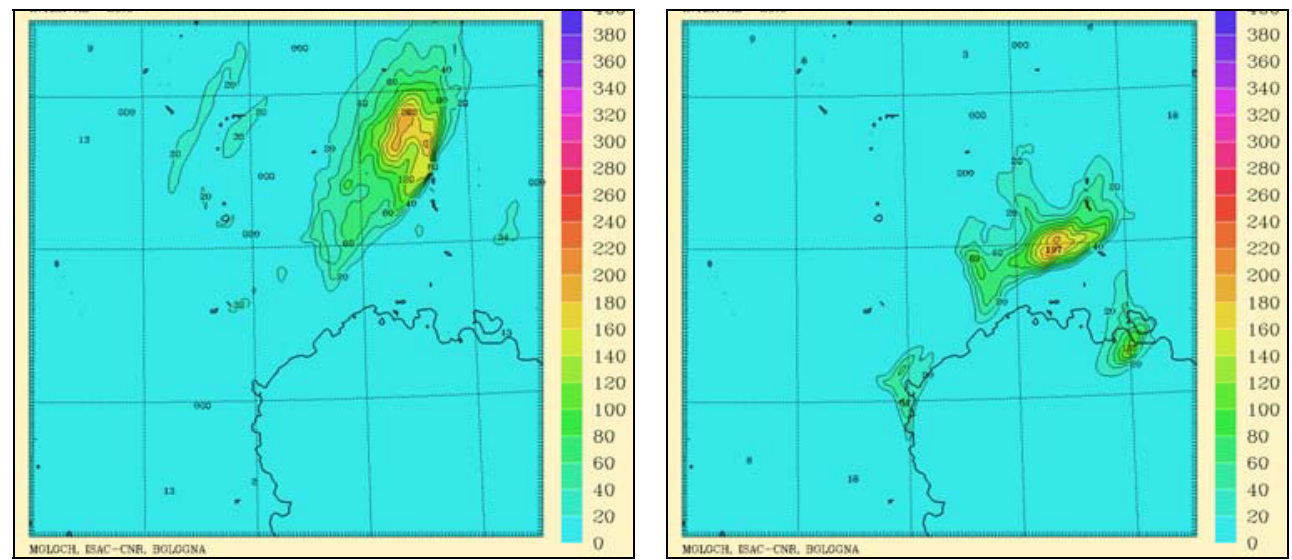

Figure 3: $12 \mathrm{~h}$ accumulated precipitation at $21 \mathrm{UTC}, 8 \mathrm{Sep} .2002$, from a $15 \mathrm{~h}$ MOLOCH simulation. Left panel: v-component increased by $2 \mathrm{~m} / \mathrm{s}$. Right panel: v-component decreased by $2 \mathrm{~m} / \mathrm{s}$. 


\section{CONCLUSION}

The main difficulty encountered in the simulation of the Gard event consists in the reproduction of the precipitation amount and correct phase lock with respect to the orographic slope. In fact the MCS develops and stays stationary for many hours in a flat region located well upstream the Massif Central and well in advance of the passage of the cold front. The concept of flow over/around based on (moist) Froude number can be useful in the early stages of the MCS evolution or in cases of stratiform flow and shallow convection (Kirshbaum and Durran, 2004). When the MCS is developed to full amplitude, its interaction with the orography is determined by dynamical processes different from those associated with orographic flow regimes. A deeper comprehension can be achieved in the context of more idealized investigations.

Acknowledgement: Raingange data and mesonet surface observation were provided in the framework of the HYDROPTIMET project - Interreg IIIb - Medocc Program by LTHE (Grenoble) and Meteo France, respectively.

\section{REFERENCES}

Bousquet O., and B. F. Smull, 2003: Observations ond impacts of upstream blocking during a widespread orographic precipitation event. Q. J. R. Meteorol. Soc., 129, 391-410.

Buzzi A., S. Davolio, M. D'Isidoro, and P. Malguzzi, 2004: The impact of resolution and of MAP reanalysis on the simulations of heavy precipitation during MAP cases. Met. Zeit., 13, 91-97.

Drofa O. V., and P. Malguzzi, 2004: Parameterization of microphysical processes in a non hydrostatic prediction model. Proc. of the $14^{\text {th }}$ International Conf. on Clouds and Precipitation (ICCP), Bologna, Italy, 1297-1300.

Ducrocq V., K. Chancibault, F. Habets, and S. Anquetin, 2003: Mesoscale modeling of a flooding storm. Application to the extreme flood of Gard. Proc. of the 5th Plinius Conf. on Mediterranean Storms, Ajaccio, France, European Geophysical Society, 43-52.

Kirshbaum D. J., and D. R. Durran, 2004: Factors governing cellular convection in orographic precipitation. J. Atmos. Sci., 61, 682-698.

Stein J., 2004: Exploration of some convective regimes over the Alpine orography. Q. J. R. Meteorol. Soc., 130, 481-502. 